\title{
Blockade by mefloquine of intercellular electrical coupling between vascular endothelial cells in the guinea-pig mesenteric arteries
}

\author{
Yoshimichi YAMAMOTO ${ }^{1,2}$ and Hikaru SUZUKI ${ }^{2}$ \\ ${ }^{1}$ Laboratory of Physiology, Nagoya City University School of Nursing \\ ${ }^{2}$ Department of Cell Physiology, Nagoya City University Graduate School of Medical \\ Sciences, Mizuho-Ku, Nagoya 467-8601, Japan
}

Received October 10, 2008; Accepted November 10, 2008

\begin{abstract}
Mefloquine, an antimalarial drug, has been reported to block exogenously transfected gap junctions composed of either $\mathrm{Cx} 36$ or $\mathrm{Cx} 50$ more potently than those composed of other connexins. Using the conventional whole-cell clamp technique, we investigated the effects of mefloquine on intercellular electrical coupling in vascular endothelial cells of guinea-pig mesenteric arteries, where expressions of $\mathrm{Cx} 40$ and $\mathrm{Cx} 43$ have been identified. Mefloquine $(50 \mu \mathrm{M})$ almost abolished the current required to impose a $10 \mathrm{mV}$ command step, leaving only rapid capacitive currents and some sustained currents after about 3 min. The relaxation of the capacitive current could be well fitted with a single exponential function. The effect of mefloquine was reversible and the time course of the current induced by the voltage step gradually changed back after mefloquine was removed. The mean input resistance and capacitance in the presence of mefloquine were $323 \mathrm{M} \Omega$ and $10.1 \mathrm{pF}$, respectively. While intercellular electrical coupling was well blocked by mefloquine $(50 \mu \mathrm{M})$, the membrane hyperpolarized from -24.0 to $-32.5 \mathrm{mV}$. The results indicate that mefloquine effectively blocks gap junctions without producing major side effects in vascular endothelial cells and that this compound is a useful tool in the investigation of gap junctions.
\end{abstract}

Key words: whole-cell clamp, gap junction blocker, multicellular preparation, connexin

\section{Introduction}

Gap junctions are involved in many physiological and pathological events (for reviews, see Mehta, 2007; Meșe et al., 2007; Trosko, 2007). Various gap junction blockers have been used to investigate the possible roles of gap junctions, however, most of them are so called "dirty drugs" having more or less undesirable effects. One of these undesirable effects is membrane depolarization. In fact, $18 \beta$-glycyrrhetinic acid depolarizes the membrane in the endothelial cells of guinea-pig mesenteric arterioles (Yamamoto et al., 1998), 18 $\alpha$ - and 18 $\beta$-glycyrrhetinic 
acids depolarize the membrane in gastrointestinal smooth muscle cells (Takeda et al., 2005), and fenamates including meclofenamic acid, flufenamic acid, niflumic acid and tolfenamic acid block gap junctions and depolarize the membrane (Harks et al., 2001). Less dirty gap junction blockers are needed to further research in this field.

In pairs of cultured neuroblastoma cells transfected with various connexins $(\mathrm{Cx} 26, \mathrm{Cx} 32$, $\mathrm{Cx} 36, \mathrm{Cx} 43, \mathrm{Cx} 46$ or $\mathrm{Cx} 50$ ), mefloquine, an antimalarial drug, blocks gap junctions composed of either Cx36 or Cx50 more potently than those composed of other connexins (Cruikshank et al., 2004). Mefloquine has only minimal nonspecific actions, one of which is the membrane depolarization of about $1 \mathrm{mV}$ observed in rat neocortical neurons (Cruikshank et al., 2004). Although higher concentrations are required, mefloquine blocks gap junctions composed of connexins other than $\mathrm{Cx} 36$ and $\mathrm{Cx} 50$. So this drug is a candidate to be a less dirty gap junction blocker.

$\mathrm{Cx} 40$ and $\mathrm{Cx} 43$ are expressed in endothelial cells of guinea-pig mesenteric arterioles (Yamamoto et al., 2001) and probably also in the upstream arteries. In the present experiments, the effects of mefloquine on vascular endothelial cells were investigated in guinea-pig mesenteric arteries. The results indicate that mefloquine effectively blocks gap junctions in vascular endothelial cells without major side effects and that this compound can be used as a useful tool to investigate gap junctions.

\section{Methods}

\section{Preparations}

Male guinea pigs, weighing 220-265 g, were anesthetized by sevoflurane inhalation and decapitated with an animal guillotine. The animals were treated ethically according to the rules of the Laboratory Animal Care and Use Committee of Nagoya City University Graduate School of Medical Sciences. Second or third order branches of mesenteric arteries (diameter 300-400 $\mu \mathrm{m})$ were dissected out from the mesenteric vasculature of the jejunoileal region. Preparations were made as described previously (Yamamoto and Suzuki, 2007). Briefly, a segment of artery was incubated in collagenase solution (nominally $\mathrm{Ca}^{2+}$-free physiological saline containing 0.5 $\mathrm{mg} / \mathrm{ml}$ collagenase; Wako Pure Chemical Industries, Ltd., Osaka, Japan) for $30 \mathrm{~min}$ at $37^{\circ} \mathrm{C}$, and the adventitial and smooth muscle layers were then removed mechanically, leaving the endothelial layer surrounded by the internal elastic lamina. The isolated endothelial layer was cut open and placed in a small chamber with the luminal surface upward, then superfused with preheated $\left(30^{\circ} \mathrm{C}\right)$ and aerated $\left(100 \% \mathrm{O}_{2}\right)$ bath solution at a constant rate $(1 \mathrm{ml} / \mathrm{min})$. The dimensions of a typical preparation were approximately $2.5 \mathrm{~mm}$ long and $0.8 \mathrm{~mm}$ wide.

\section{Electrophysiological techniques}

A patch electrode was applied to one of the endothelial cells, and conventional whole-cell clamp experiments were performed. Current and voltage signals were acquired using a MultiClamp 700A system (Molecular Devices, Sunnyvale, CA, USA). These signals were digitized with a Digidata 1322A data acquisition system (Molecular Devices). The sampling rate was always five times higher than the cutoff frequency $(-3 \mathrm{~dB})$ of a low-pass Bessel filter. 
Voltage clamp protocols were controlled with pCLAMP 10 software (Molecular Devices). The liquid junction potential calculated as the potential of the bath solution with respect to the pipette was $+15.5 \mathrm{mV}$ (Barry and Lynch, 1991) and compensated manually after each experiment.

\section{Solutions and chemicals}

The composition of the standard bath solution was (mM) $\mathrm{NaCl}, 146 ; \mathrm{KCl}, 5.4 ; \mathrm{CaCl}_{2}, 1.8$; $\mathrm{MgCl}_{2}$, 1; HEPES, 10; glucose, 5. The $\mathrm{pH}$ was adjusted to 7.3 using $\mathrm{NaOH}$. The pipette solution contained (mM) KCl, 20; K-aspartate, 128; $\mathrm{MgCl}_{2}$, 1; HEPES, 10; glucose, 5; EGTA, 1; ATP-2Na, 2. The $\mathrm{pH}$ was adjusted to 6.9 using $\mathrm{KOH}$. Mefloquine was obtained from Sigma (St. Louis, MO, USA) and dissolved in DMSO to make a stock solution of $10^{-1} \mathrm{M}$.

\section{Statistics}

Numerical data are represented as the mean $\pm \mathrm{SD}$, with $\mathrm{n}$ indicating the number of measurements. For statistical evaluation, a $P$ value $<0.05$ was considered to be significant.

\section{Results}

The preparations used in the present experiments were sheets of freshly isolated endothelium, which consisted of many electrically coupled endothelial cells. The conventional whole-cell clamp method was applied to one of the endothelial cells, and changes in the time course of the current required to impose a $10 \mathrm{mV}$ voltage clamp step were used to determine the extent of coupling between cells (de Roos et al., 1996, Yamamoto et al., 1998). It can be seen in Fig. 1 that mefloquine $(50 \mu \mathrm{M})$ almost abolished the current required to impose a $10 \mathrm{mV}$ command step after about 3 min (Fig. 1A). In the presence of mefloquine, only rapid capacitive currents and some sustained currents were observed. The effect of mefloquine was reversible and the time course of the current induced by the voltage step gradually changed back after mefloquine was removed (Fig. 1B). The process of recovery was rather slow and it took more than $10 \mathrm{~min}$ to get the current response comparable to the control.

The relaxation of capacitive current induced by a step depolarization in the presence of mefloquine $(50 \mu \mathrm{M})$ could be well fitted with a single exponential function (Fig. 2B). The input resistance $\left(R_{\text {in }}\right)$ and capacitance $\left(C_{\text {in }}\right)$ were calculated according to the following equations:

$$
R_{\text {in }}=\left(V_{\mathrm{P}}-R_{\mathrm{a}} I_{\mathrm{ss}}\right) / I_{\mathrm{ss}} \text { and } C_{\mathrm{in}}=\tau / R_{\mathrm{a}}
$$

where $V_{\mathrm{P}}$ is the amplitude of voltage step, $I_{0}$ the membrane current at the beginning of voltage step, $I_{\mathrm{ss}}$ the steady-state current, $R_{\mathrm{a}}$ the access resistance $\left(R_{\mathrm{a}}=V_{\mathrm{P}} / I_{0}\right)$ and $\tau$ the time constant of capacitive current relaxation (Fig. 2A). $R_{\text {in }}$ and $C_{\text {in }}$ in the presence of mefloquine were $323 \pm 94$ $\mathrm{M} \Omega$ and $10.1 \pm 1.5 \mathrm{pF}$, respectively $(\mathrm{n}=13)$.

Mefloquine hyperpolarized the membrane. At the time when the intercellular electrical coupling was well blocked by mefloquine $(50 \mu \mathrm{M})$, the membrane had hyperpolarized in all 13 preparations examined (Fig. 3A). The membrane potentials in the absence and the presence of mefloquine were $-24.0 \pm 2.9 \mathrm{mV}$ and $-32.5 \pm 2.8 \mathrm{mV}$, respectively $(\mathrm{n}=13)$, and these were 
A

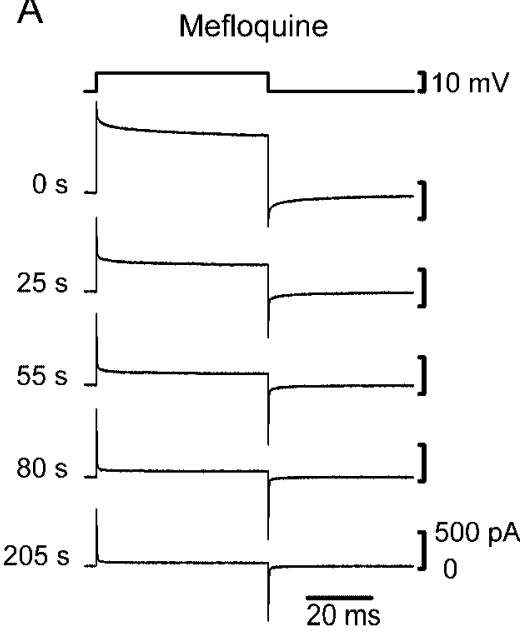

B

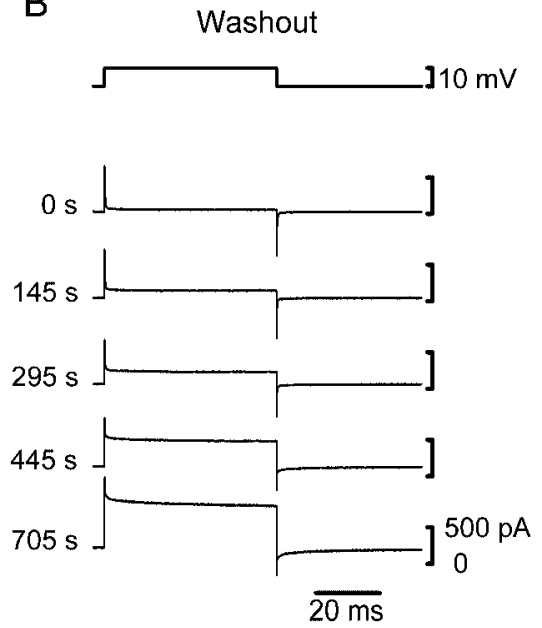

Fig. 1. Effect of mefloquine $(50 \mu \mathrm{M})$ on membrane currents induced by step depolarizations (top traces). Holding potential was $-15.5 \mathrm{mV}$. Mefloquine was applied at time 0 in A and almost abolished the current required to impose a $10 \mathrm{mV}$ command step after about $3 \mathrm{~min}$. The time of mefloquine application was about $24 \mathrm{~min}$. Washout commenced at time 0 in $\mathrm{B}$ and required more than 10 min to restore to control levels. Signals were filtered at a cut-off frequency of $10 \mathrm{kHz}$. Time scale shown in the bottom traces applies to all.

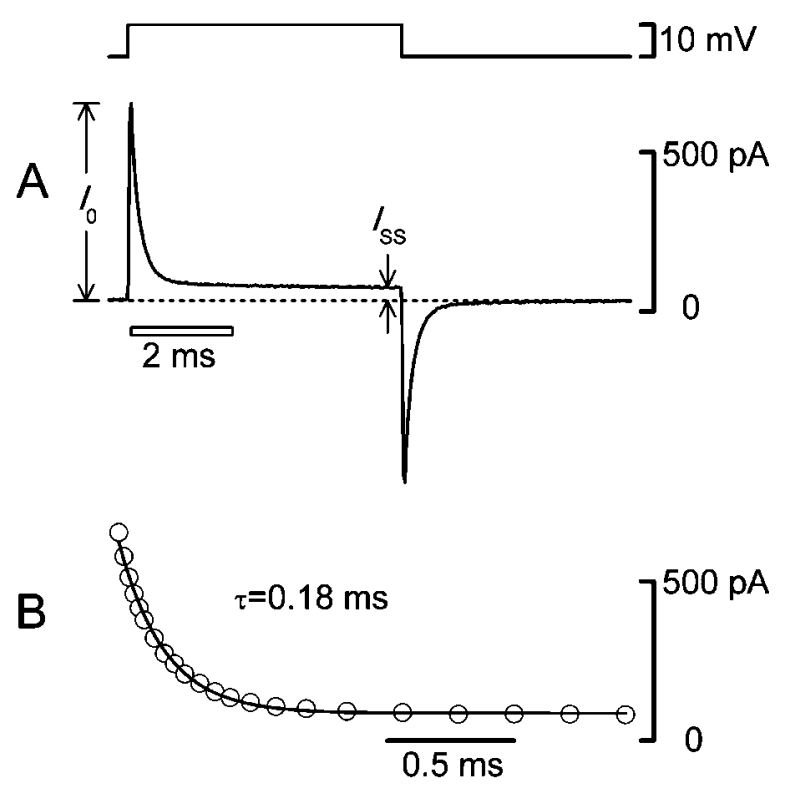

Fig. 2. A: Current required to impose a $10 \mathrm{mV}$ voltage clamp step (top trace) in the presence of mefloquine $(50 \mu \mathrm{M})$. Holding potential was $-15.5 \mathrm{mV}$. $I_{0}$ is membrane current at the beginning of voltage step and $I_{\mathrm{ss}}$ is steady-state current. Broken line represents the holding current level. B: The decay of the capacitive current during the period indicated by the box in A was plotted in an expanded time-scale $(O$, the number of data points was reduced for clarity). It could be well fitted with a single exponential function (continuous curve). 
Control Mefloquine Washout

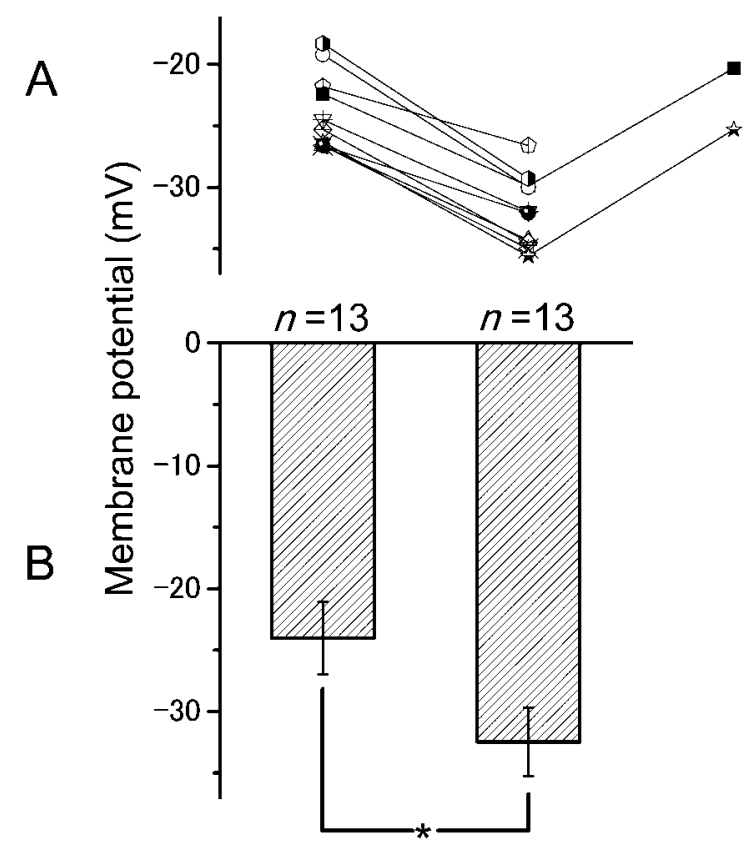

Fig. 3. Effect of mefloquine $(50 \mu \mathrm{M})$ on membrane potentials. A: Change in the membrane potentials of 13 preparations before and after the application of mefloquine. In two preparations the recording was continued after the washout of mefloquine. Each symbol represents data from a separate experiment. B: Average membrane potentials in the absence and presence of mefloquine. Error bars represent the SD.

*, significant difference (Student's paired $t$ test).

significantly different statistically (Fig. 3B). While continuous recordings for more than $30 \mathrm{~min}$ was not easy, recovery from the effect of mefloquine was observed in two preparations where the membrane potential returned to the control level after the washout (Fig. 3A).

\section{Discussion}

Mefloquine reversibly blocked gap junctions in vascular endothelial cells of the guinea-pig mesenteric arteries in the present experiments. The input resistance was more than $300 \mathrm{M} \Omega$ in the presence of $50 \mu \mathrm{M}$ mefloquine. Although no data are available about the input resistance while gap junctions were completely blocked in multicellular preparations, this value might be lower than expected, possibly indicating that some gap junctions might be still functioning at this concentration. The value of $1.7 \mathrm{G} \Omega$ reported in cultured guinea-pig coronary endothelial cells (Daut et al., 1988) may serve as a reference. Even if the blocking action of mefloquine at this concentration may not be perfect, intercellular electrical coupling seemed to be effectively blocked because, in the presence of mefloquine, the relaxation of the capacitive current could be well fitted with a single exponential function indicating a simple RC-network load (Lindau and Neher, 1988). As the input resistance is $500 \mathrm{M} \Omega$ in the presence of $18 \beta$-glycyrrhetinic acid (40 
$\mu \mathrm{M}$ ) in endothelial cells of guinea-pig mesenteric arterioles (Yamamoto et al., 1998), mefloquine seems to be as potent as $18 \beta$-glycyrrhetinic acid as a gap junction blocker.

Mefloquine blocks exogenously transfected gap junctions composed of either Cx36 or Cx50 more potently than those composed of other connexins, yet higher concentration $(25 \mu \mathrm{M})$ is required to block the natural gap junctions composed of $\mathrm{Cx} 36$ in brain slices from the rat neocortex (Cruikshank et al., 2004). The authors claim that concentrations of the drug at the recording site may be lower than in the bath solution as a result of slow drug diffusion through the slices (Cruikshank et al., 2004). Alternatively exogenously expressed Cx36 and Cx50 may be somewhat different from their natural form in terms of their sensitivity to mefloquine.

Mefloquine hyperpolarized the membrane in the present experiments. Although this compound may have a side effect of modifying the activities of ionic channels which determine the resting membrane potential, there is another possibility that should be considered. During the preparation process a proportion of the cells, particularly those at the cut edges, will have been damaged making the final preparation a mosaic of healthy and damaged cells. Giga seals cannot be made on the damaged cells, so only the healthy cells can be patched and recorded. So mefloquine might merely allow patched cells to restore their own resting membrane potentials by isolating them electrically from the neighboring cells which may have been damaged and depolarized. The hyperpolarizing effect was also reversible and the potential returned to the control level after washing out mefloquine.

$\mathrm{Ca}^{2+}$-activated channels including $\mathrm{K}^{+}$channels are activated by acetylcholine causing the membrane to become hyperpolarized in endothelial cells (Yamamoto et al., 1999; Yamamoto and Suzuki, 2005; Yamamoto and Suzuki, 2007). This response was well preserved after intercellular electrical coupling had been blocked by mefloquine (Y. Yamamoto, unpublished observation). Although more research is required to draw a conclusion, the results presented in this paper indicate that mefloquine effectively blocks gap junctions without producing major side effects in vascular endothelial cells and that this compound is a useful tool in the investigation of gap junctions.

\section{References}

Barry, P.H. and Lynch, J.W. (1991). Topical Review. Liquid junction potentials and small cell effects in patch clamp analysis. J. Membrane Biol. 121: 101-117.

Cruikshank, S.J., Hopperstad, M., Younger, M., Connors, B.W., Spray, D.C. and Srinivas, M. (2004). Potent block of Cx36 and Cx50 gap junction channels by mefloquine. Proc. Natl. Acad. Sci. U.S.A. 101: 12364-12369.

Daut, J., Mehrke, G., Nees, S. and Newman, W.H. (1988). Passive electrical properties and electrogenic sodium transport of cultured guinea-pig coronary endothelial cells. J. Physiol. (Lond.) 402: 237254.

de Roos, A.D.G., van Zoelen, E.J.J. and Theuvenet, A.P.R. (1996). Determination of gap junctional intercellular communication by capacitance measurements. Pflügers Arch. 431: 556-563.

Harks, E.G.A., de Roos, A.D.G., Peters, P.H.J., de Haan, L.H., Brouwer, A., Ypey, D.L., van Zoelen, E.J.J., and Theuvenet, A.P.R. (2001). Fenamates: a novel class of reversible gap junction blockers. $J$. Pharmacol. Exp. Ther. 298: 1033-1041.

Lindau, M. and Neher, E. (1988). Patch-clamp techniques for time-resolved capacitance measurements 
in single cells. Pflügers Arch. 411: 137-146.

Mehta, P.P. (2007). Introduction: a tribute to cell-to-cell channels. J. Memb. Biol. 217: 5-12.

Meşe, G., Richard, G. and White, T.E. (2007). Gap junctions: basic structure and function. J. Invest. Dermatol. 127: 2516-2524.

Takeda, Y., Ward, S.M., Sanders, K.M. and Koh, S.D. (2005). Effects of the gap junction blocker glycyrrhetinic acid on gastrointestinal smooth muscle cells. Am. J. Physiol. Gastrointest. Liver Physiol. 288: G832-G841.

Trosko, J.E. (2007). Gap junctional intercellular communication as a biological "Rosetta Stone" in understanding, in a systems biological manner, stem cell behavior, mechanisms of epigenetic toxicology, chemoprevention and chemotherapy. J. Memb. Biol. 218: 93-100.

Yamamoto, Y., Fukuta, H., Nakahira, Y. and Suzuki, H. (1998). Blockade by $18 \beta$-glycyrrhetinic acid of intercellular electrical coupling in guinea-pig arterioles. J. Physiol. (Lond.) 511: 501-508.

Yamamoto, Y., Imaeda, K. and Suzuki, H. (1999). Endothelium-dependent hyperpolarization and intercellular electrical coupling in guinea-pig mesenteric arterioles. J. Physiol. (Lond.) 514: 505513.

Yamamoto, Y., Klemm, M.F., Edwards, F.R. and Suzuki, H. (2001). Intercellular electrical communication among smooth muscle and endothelial cells in guinea-pig mesenteric arterioles. J. Physiol.(Lond.) 535: 181-195.

Yamamoto, Y. and Suzuki, H. (2005). Dependency of endothelial cell function on vascular smooth muscle cells in guinea-pig mesenteric arteries and arterioles. J. Smooth Muscle Res. 41: 77-85.

Yamamoto, Y. and Suzuki, H. (2007). Effects of increased intracellular $\mathrm{Cl}^{-}$concentration on membrane responses to acetylcholine in the isolated endothelium of guinea pig mesenteric arteries. $J$. Physiol. Sci. 57: 31-41. 